Check for updates

The BMJ

Cite this as: BMJ 2021;372:n372 http://dx.doi.org/10.1136/bmj.n372 Published: 08 February 2021

\title{
Covid-19: South Africa pauses use of Oxford vaccine after study casts doubt on efficacy against variant
}

\section{Elisabeth Mahase}

Rollout of the Oxford-AstraZeneca covid-19 vaccine in South Africa has been paused after a study in 2000 healthy and young volunteers reported that it did not protect against mild and moderate disease caused by the new variant (501Y.V2) that emerged there.

The study, which has not been published and was seen by the Financial Times, ${ }^{1}$ looked at the efficacy of the vaccine against the 501Y.V2 variant-which accounts for around $90 \%$ of cases in South Africa-in HIV negative people. While reports suggested that the vaccine was ineffective at preventing mild to moderate disease in that population, no data have been made available to the public. Efficacy against severe covid-19, hospital admissions, and deaths has not been determined.

South Africa's health minister, Zweli Mkhize, said that other vaccines, including those from Pfizer and Janssen, would be rolled out while the Oxford-AstraZeneca vaccine was reviewed.

The Janssen (Johnson \& Johnson) vaccine uses similar technology to the Oxford-AstraZeneca vaccine and has shown $57 \%$ efficacy when tested in South Africa. This is lower than against other variations of the SARS-CoV-2 virus-a trend seen in all vaccines so far tested against this variant. ${ }^{2}$

Shabir Madhi, chief investigator on the Oxford trial in South Africa and professor of vaccinology, said, "Recent data from a study in South Africa sponsored by Janssen which assessed moderate to severe disease, rather than mild disease, using a similar viral vector, indicated that protection against these important disease endpoints was preserved.

"These findings recalibrate thinking about how to approach the pandemic virus and shift the focus from the goal of herd immunity against transmission to the protection of all at-risk individuals in the population against severe disease.”

\section{Booster jabs}

Meanwhile, Sarah Gilbert, professor of vaccinology at the University of Oxford who leads the Oxford vaccine team, said that efforts were already under way to develop booster jabs against new variants. Andrew Pollard-who leads the Oxford trials in the UK, South Africa, and Brazil-explained this process in a recent interview with The BMJ. ${ }^{3}$

Commenting on the unpublished paper, Peter Openshaw, professor of experimental medicine at Imperial College London, said, "The information we have is very limited, but the trial seems to have been restricted to HIV negative younger people [with a] mean age [of] 31-about 1000 in the placebo arm and 1000 in the active vaccine group. In this age group and with these numbers, the effect on severe disease is going to be hard to estimate. Without seeing results in detail it isn't possible to be sure how firm these conclusions are.

"However, if the press reports are correct it does seem of concern that protection against disease was not shown. The findings of the Novavax vaccine trial of $60 \%$ efficacy in the prevention of disease of any severity in HIV negative volunteers in South Africa might also suggest that vaccines will need to be updated in line with emerging mutations of the virus."

1 Mancini DP, Kuchler H, Pilling D, Cookson C, Cotterill J. Oxford/AstraZeneca jab fails to prevent mild and moderate Covid from S African strain, study shows. Financial Times 2021 Feb 7. https://www.ft.com/content/e9bbd4fee6bf-4383-bfd3-be64140a3f36.

2 Mahase E. Covid-19: Novavax vaccine efficacy is $86 \%$ against UK variant and 60\% against South African variant. BMJ 2021;372:n296. doi: 10.1136/bmj.n296 pmid: 33526412

3 Mahase E. How the Oxford-AstraZeneca covid-19 vaccine was made. BMJ 2021;372:n86. doi: 10.1136/bmj.n86 pmid: 33436419

This article is made freely available for use in accordance with BMJ's website terms and conditions for the duration of the covid-19 pandemic or until otherwise determined by BMJ. You may use, download and print the article for any lawful, non-commercial purpose (including text and data mining) provided that all copyright notices and trade marks are retained. 